\title{
Introducción. Atención Temprana: Desarrollo y Educación
}

\section{Introduction. Early attention: Development and Education}

\author{
Purificación Sierra García \\ Universidad Nacional de Educación a Distancia
}

\author{
Pilar Gutiez Cuevas \\ Universidad Complutense de Madrid
}

Desde mediados del siglo XX el ámbito de la Atención temprana se ha alzado como un campo esencial de trabajo que persigue el objetivo de la detección e intervención temprana en las alteraciones del desarrollo y en las condiciones que la provocan o que son agentes potenciales de provocarlas. Dichos agentes y factores de riesgo se encuentran tanto en el ámbito biológico como en el psicológico, social y educativo.

El desarrollo y la educación son fenómenos complejos y multideterminados. Por ello, el abordaje de las necesidades de los niños de entre 0 y 6 años con alteraciones o con riesgo de padecerlas, así como la intervención a llevar a cabo, no puede ser una tarea unidimensional y unidisciplinar. Al contrario, la Atención Temprana debe entenderse como una actividad Interdisciplinar que debe tender a la transdisciplenaridad.

Los orígenes de las alteraciones del desarrollo así como las vías de intervención son tan variadas que requieren una visión holística y un trabajo conjunto y acompasado, en la seguridad de que el todo es mucho más que la suma de las partes.

Los programas de prevención e intervención precoz han evolucionado exponencialmente en las últimas décadas al amparo de diversas conceptualizaciones de lo que es y se entiende por Atención temprana, a pesar de ser un campo consolidado. Por ello, resulta oportuno ofrecer una mirada sobre el panorama actual de la AT en nuestro país, sus principales líneas de trabajo y sus perspectivas futuras. Este es, precisamente el objetivo de este monográfico, presentar una serie de artículos que nos permitan obtener una mirada general y actual del campo de la Atención Temprana en nuestro país, con la seguridad de que el mejor conocimiento de la realidad nos permite una intervención más ajustada de todos los implicados en el objetivo de optimización del desarrollo.

El primer artículo está dedicado a una reflexión, desde nuestro punto de vista absolutamente necesaria, acerca del concepto mismo de AT a la luz de las premisas sobre las que se construye y que dieron lugar al Libro Blanco de la AT y de su evolución en nuestro país. El autor (José Antonio Luengo) realiza un interesante y aclaratorio ejercicio de análisis del "programa" y de la "hoja de ruta" inicial de la AT y los puntos fuer-

La correspondencia sobre este artículo debe enviarse a las autoras a los E-mails: psierra@psi.uned.es - pigutiez@psi.ucm.es tes y debilidades de su implementación en el panorama español del siglo XXI.

El lector encontrará en el siguiente artículo, firmado por Pilar Gútiez y Elisa Ruiz Veerman, una revisión profunda y a la vez sintetizada del devenir de la AT, sus conceptos clave y las coordenadas de comprensión de esta disciplina. Por medio de esta exposición, se ofrece un panorama completo de qué es y cómo se organiza la AT en nuestro país. En este marco, ha de interpretarse y situarse el artículo firmado por Carmen de Andrés y Castellar López-Guinea. que nos acercan a uno de los agentes esenciales de intervención: la familia. La AT ha hecho suya la máxima de la familia como contexto de desarrollo, de manera que es, no sólo un aliado fundamental en la intervención eficaz sino objeto de atención e intervención en sí mismo. De nuevo, cabría preguntarse si esta premisa forma parte, realmente, del funcionamiento de la AT. En un estudio descriptivo, las autoras presentan cuál es la situación de la atención a las familias en el entorno de la Comunidad Autónoma de Madrid, poniendo de relieve que aunque se han producido avances en la integración de la Familia en la AT, es necesaria una mayor y mejor coordinación de los diversos agentes institucionales.

Una vez expuesta una reflexión sobre las coordenadas fundamentales de la disciplina y realizada una breve incursión su implementación en el panorama institucional, Mercedes Valle, Rocío Mateo y Pilar Gútiez, nos acercan a las características de uno de las poblaciones que, por antonomasia, son destinatarios de la AT: los niños prematuros. Así mismo, se resalta la importancia de realizar una adecuada valoración del desarrollo neuropsicológico de estos niños como indicador de su trayectoria de desarrollo, lo que supone, al fin, un dato esencial para una intervención eficaz.

En esta línea, Amaya Sterner y Cintia Rodríguez, nos presentan un sugerente estudio ideográfico de caso único, con un bebé de riesgo entre los 9 y los 16 meses. La propia estrategia de estudio, desde una perspectiva semiótica, añade una valiosa vía de comprensión a nuestro conocimiento de indicadores tempranos de Trastornos del Espectro Autista.

El curso natural del desarrollo infantil se desarrolla en diferentes contextos (entendidos como entornos físicos y psicológicos). Sabemos que el desarrollo temprano tiene como principal entorno la familia pero en las últimas décadas, de forma casi simultánea/paralela, la escuela cumple un papel temprano y esencial en el 
progreso psicológico de los niños. Los tres últimos artículos de este monográfico se organizan alrededor de esta realidad.

Laura Méndez e Isabel Yela, nos adentran en el papel de los Equipos de Atención Temprana para recalar en el papel del psicólogo educativo como profesional especialmente implicado en la evaluación e intervención que podríamos denominar "transversal", en el sentido de encontrarse al servicio de y coordinado con los responsables educativos de los centros y la familia, teniendo en el centro de su interés el apoyo educativo al niño. Realizar esta tarea, y ello es lo que nos presentan las autoras, supone un acto de reflexión (poco frecuente, por otra parte) acerca de cuáles son las competencias profesionales del psicólogo educativo, entendiendo dichas competencias como el conjunto de habilidades (conceptuales, procedimentales y actitudinales) que presentan de forma conceptual e integradas en una propuesta de trabajo.

Complementariamente, Helena López nos presenta un estudio descriptivo realizado en los Servicios Educativos de la Comunidad de Madrid, en el universo de todos los Equipos de Orientación Educativa y Psicopedagógica, en el que se nos muestra, precisamente, cómo se organiza y se lleva a cabo la detección, evaluación e intervención de los niños a lo largo de toda la Etapa de Educación Infantil. Sus conclusiones son un buen elemento de reflexión acerca de las tareas de los Equipos y de, curiosamente, la demanda de competencias profesionales en la línea que se mencionaban en el artículo anterior.

Por último, Purificación Sierra y Javier Moya cierran el monográfico con un artículo que se adentra en una de las áreas del desarrollo de especial relevancia y en la que todos los implicados en el ámbito educativo tienen/pueden tener un papel clave: generar y asegurar la sensación del niño de sentirse seguro y querido. Maestros, psicólogos Educativos, Pedagogos, deben adquirir la sensibilidad, los conocimientos y las estrategias (las competencias) necesarias para poder detectar indicadores de alteración en el desarrollo de la vinculación afectiva de apego o del riesgo de padecerla. Dichas alteraciones no sólo son subsidiarias de otras alteraciones sino que pueden constituir en sí misma una Necesidad Especial. Los autores presentan las claves de comprensión del comportamiento infantil en el aula a la luz de esta perspectiva y algunas pautas de intervención en este ámbito del desarrollo.

Como puede verse, hemos intentado una revisión necesariamente incompleta de profesionales y temas de interés en la Atención Temprana. En cualquier caso, nuestro objetivo ha sido acercar al lector a esta disciplina que tiene, como seña de identidad construir posibilidades de desarrollo. 